\title{
General Medicine Open
}

\section{Cardiac amylo1dosis}

\section{Ravza Yılmaz, Omer Faruk Unal, Zuhal Bayramoglu*, Ali Aslan Demir and Memduh Dursun}

Radiology Department, Istanbul Medical Faculty, Istanbul University, Turkey

We present the case of a 62 year-old male who had clinical signs of congestive heart failure, as angina pectoris, progressive shortness of breath and lower extremity edema. In the echocardiography, there was concentric left ventricular thickening, biatrial enlargement and increasing echogenicity of the myocardium with normal biventricular dimensions.

He was referred to the department of radiology after these findings and Cardiac MRI (CMRI) was performed to diagnose the cause of restrictive cardiomyopathy .On the short-axis cine images, there were concentric thickening and systolic disfunctions of the left and right ventricules. Delayed-enhanced MRI (DE-MRI) showed circumferential subendocardial enhancement extending into the biatrial and biventricular myocardial wall and also demonstrated pleural effusion (Figure 1A).Also it was seen a circumferential subendocardial hypointensity on 3D scar imaging (Figure 1B). Despite aggressive treatment, the patient died. Postmortem analysis demonstrated amyloid cardiac deposition including involvement of the coronary microvasculature. Electron microscopy revealed myocyte compression injury from amyloid infiltration.

Copyright: (C)2017 Y1lmaz R. This is an open-access article distributed under the terms of the Creative Commons Attribution License, which permits unrestricted use, distribution, and reproduction in any medium, provided the original author and source are credited.

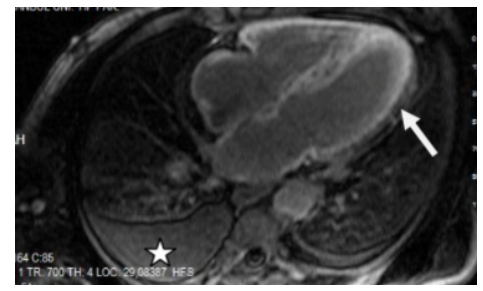

$1 \mathrm{~A}$

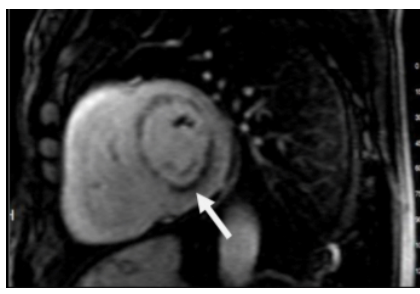

$1 \mathrm{~B}$
Figure 1A and 1B

The most common cause of restrictive cardiomyopathy is amyloidosis which is caused by extracellular deposition of beta-amyloid protein [1]. Cardiac amyloidosis is a clinical condition including the association of findings on history, physical examination and cardiac imaging. CMRI may be preferred as a diagnostic method in cardiac amyloidosis.

\section{References}

1. Vanden Driesen RI, Slaughter RE, Strugnell WE (2006) MR findings in cardiac amyloidosis. AJR Am J Roentgenol 186: 1682-1685.
Correspondence to: Zuhal Bayramoglu, Radiology Department, Istanbul Medical Faculty, Istanbul University, Turkey, E-mail: incezuhal@yahoo.com

Received: June 04, 2017; Accepted: June 26, 2017; Published: June 28, 2017 